\title{
REVIEW
}

\section{Recent advances in fruit crop genomics}

\author{
Qiang XU, Chaoyang LIU, Manosh Kumar BISWAS, Zhiyong PAN, Xiuxin DENG (ه) \\ Key Laboratory of Horticultural Plant Biology (Ministry of Education), Huazhong Agricultural University, Wuhan 430070, China
}

\begin{abstract}
In recent years, dramatic progress has been made in the genomics of fruit crops. The publication of a dozen fruit crop genomes represents a milestone for both functional genomics and breeding programs in fruit crops. Rapid advances in high-throughput sequencing technology have revolutionized the manner and scale of genomics in fruit crops. Research on fruit crops is encompassing a wide range of biological questions which are unique and cannot be addressed in a model plant such as Arabidopsis. This review summarizes recent achievements of research on the genome, transcriptome, proteome, miRNAs and epigenome of fruit crops.
\end{abstract}

Keywords fruit crops, fruit biology, gene function, genomics

\section{Introduction}

Fruit crops include a wide range of plant species that can be classified into several groups, including evergreen (e.g. orange and papaya), deciduous (e.g. apple and peach), herbaceous (e.g., banana and strawberry), and vine (e.g., grapevine and kiwifruit) species. Fruit crops are of great economic importance; the gross world production reached 263 billion tonnes, accounting for about $20 \%$ of all agricultural products in 2011 (FAO statistics). Fruit is also an important part of the human diet and contains abundant components beneficial to human health.

Numerous efforts have been made to improve the agronomic and economic traits with the aim of increasing production and enhancing the quality, resistances to the stresses, postharvest and nutritional properties. Manipulation at the gene level is a potential tool to achieve these goals, and increasing efforts have been directed to this area, including the genetic improvement of target traits via gene targeting. To this end, identification of key genes and elucidation of gene function is essential. Classical approaches depend mainly on forward genetics, and

Received March 13, 2014; accepted March 22, 2014

Correspondence: xxdeng@mail.hzau.edu.cn identify the key genes (loci) based on genetic maps produced from large genetic populations. Traditional genetic experiments are rather complicated in most fruit crops due to their biologic characteristics, such as long life cycle, large tree canopy or asexual reproduction (apomixis). As a result, such genetic studies are long and expensive, often requiring large areas of land. Over the past decade, the field of fruit crop genomics has advanced rapidly and provided an alternative way to identify potential key genes, particularly those controlling the interesting and specific traits in fruits that cannot be studied in model plants such as Arabidopsis and rice. These aims have been rapidly facilitated by recent emergence of next generation (Next-Gen) sequencing technology (Illumina, SOLiD and 454 platforms) [1]. This sequencing-based approach has attracted fruit crop researchers since it is convenient, efficient, and fast, and requires relatively little space compared with classic genetic studies. We believe that the sequencing-based approach will become more popular for basic research on fruit crops, particularly as a direct step to the gene level, which is a necessary step for understanding the molecular basis of traits of interest. In the near future, multiple omics-based research strategies will form the basis for the next wave of advancements in fruit crop research, particularly as the number of sequenced genomes is increasing rapidly. This review summarizes recent studies of the genomes, transcriptomes, proteomes, miRNAs and epigenomes of fruit crops (Fig. 1).

\section{Genomic research on fruit crops}

\subsection{The genome}

To date, the genomes of 12 fruit crops have been sequenced (Table 1). The first fruit crop genome to be published was that of grapevine in 2007. This was also the fourth flowering crop to be sequenced [11]. Sequencing of a transgenic genotype of papaya followed in 2008 [2]. These genomes were sequenced using Sanger sequencing technology, an accurate but expensive and time-consuming process. The emergence of Next-Gen sequencing plat- 


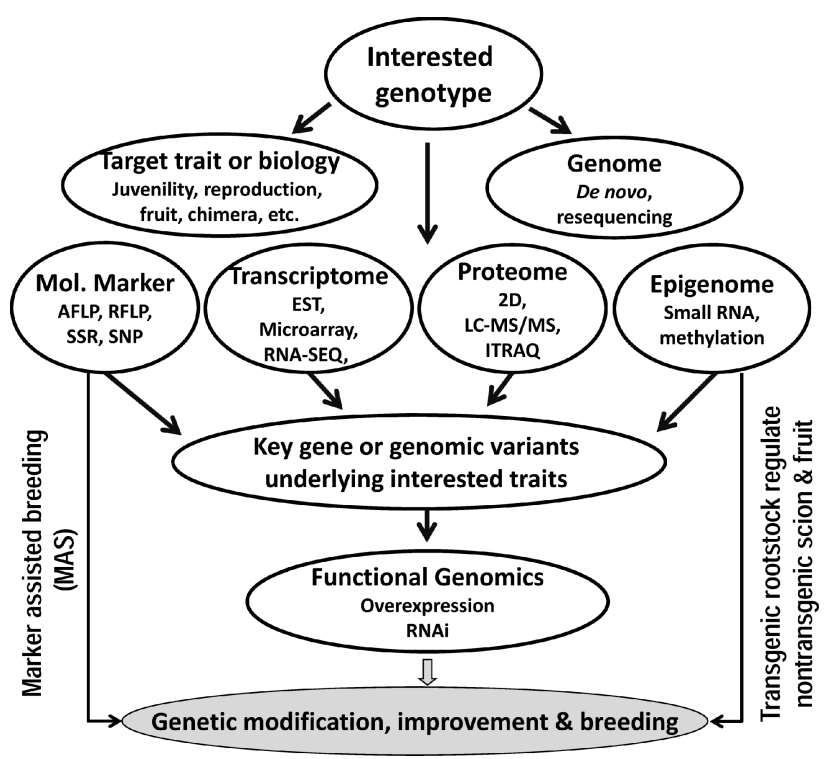

Fig. 1 Genomics studies in fruit crops and their potential roles for interested trait dissection, genetic modification and breeding

forms (e.g., Illumina; SoLID, Life Technologies; 454, Roche), and the recent reduced cost and improved efficiency of such technology, has dramatically accelerated the sequencing of fruit crops. The apple genome was assembled using a combination of Sanger and 454 sequencing reads [5] and such combinatorial strategies were also implemented in the de novo genome assemblies of strawberry [4], banana [6] and pear [9]. There are also several instances of de novo genome assembly that employed Next-Gen data alone, such as sequencing of sweet orange [3] and kiwifruit [10].

Evolution is one of the interesting areas that can be investigated by de novo genome analysis. Following interpretation of the genome-scale data within the grapevine genome, and comparison of this data with those of Arabidopsis, rice and poplar, Jaillon et al. [11] postulated the existence of an ancient whole genome triplication event in all eudicot genomes. This model is widely accepted; thus, the grapevine genome provides a reference for whole genome duplication (WGD) analysis. Furthermore, a recent WGD event was identified and the followed chromosome fusion events contributed to the speciation of apple [5]. Whole genome data are also powerful for analysis of speciation or species origin. Sequencing of the sweet orange genome and re-sequencing of progenitors, including pummelo and mandarin, revealed the origin of cultivated orange [3].

Biological questions can also be addressed from the genome data. From the genomes of papaya and date palm it was possible to identify sex-linked chromosome or genomic regions. These are important, not only for the understanding of sex differentiation in plants, but are also beneficial for breeding, because female fruit-producing trees are generally of greater agricultural significance than male trees [2,7]. Research on sweet orange demonstrated that the high content of vitamin $\mathrm{C}$ in fruit is due to the high expression of genes involved in the galacturonate pathway, particularly the rate-limiting enzyme of the galacturonate pathway, GalUR. The recent expansion of GalUR gene family may provide a genomic basis for regulating vitamin C production [3].

\subsection{Molecular markers}

Simple sequence repeat (SSR) markers have been increasingly used for the analysis of fruit crops and have contributed significantly to fruit tree breeding programs. The most common uses of SSR markers in fruit tree research include characterization of germplasm evaluation, genetic diversity, cultivar identification and linkage map construction $[12,13]$. Due to the requirement for prior sequence information, use of SSRs has benefited from the availability of rapidly accumulating genomic resources including expressed sequence tags (EST), whole genome sequences and BAC end sequences. These resources allow data mining by using pipelines composed of SSR

Table 1 Published de novo genomes of fruit crops

\begin{tabular}{|c|c|c|c|c|c|}
\hline$\overline{\text { Species }}$ & Common name & Genome size/Mb & Gene number & $\mathrm{TE}^{1}$ percentage & Reference \\
\hline$\overline{\text { Carica papaya }}$ & Papaya & 372 & 24746 & 52.0 & {$[2]$} \\
\hline Citrus sinensis & Sweet orange & 367 & 29655 & 20.5 & [3] \\
\hline Fragaria vesca & Strawberry & 240 & 34809 & 22.0 & [4] \\
\hline Malus domestica & Apple & 742 & 57386 & 42.4 & [5] \\
\hline Musa acuminata & Banana & 523 & 36542 & 43.7 & [6] \\
\hline Phoenix dactylifera & Date palm & 658 & 25059 & - & [7] \\
\hline Prunus persica & Peach & 265 & 27852 & 29.6 & [8] \\
\hline Pyrus bretschneideri & Pear & 527 & 42812 & 53.1 & [9] \\
\hline Actinidia chinensis & Kiwifruit & 758 & 39040 & 36.0 & {$[10]$} \\
\hline Vitis vinifera & Grapevine & 490 & 33514 & 41.4 & {$[11]$} \\
\hline
\end{tabular}

Note: ${ }^{1} \mathrm{TE}$, transposable element. 
identification and primer design programs. Many of the pipelines are publically accessible, including MISA (MIcro SAtellite identification tool), SSR hunter, SSR Locator [14], Phobos [15] and SPUTNIK. Such programs identify SSR motifs and provide an overview of the distribution and frequency of SSRs in the entire genome [16,17].

SNPs (single nucleotide polymorphisms) have made the most impact as molecular markers in recent years and have revolutionized the scale, number and efficiency of molecular markers in many ways. SNPs are highly abundant in the genome and are amenable to marker development and high-throughput genotyping. The reduced cost of Next-Gen sequencing provides an opportunity for the development of genome wide SNP markers, which have wide applications in genomic research. SNP markers were generated for phylogenetic and population structure determination of citrus germplasm [13] and in grape domestication [18]. Three peach genomes were sequenced and mined for high-density SNP markers to be used in genotyping, map construction and quantitative trait loci analysis in populations [19]. The identified markers can ultimately be used in agronomic trait dissection and breeding. SNP markers in apple complex traits analysis showed that $3 \%$ to $25 \%$ of phenotypic variation could be explained by the identified markers [20]. By using a Next-Gen sequence-based mapping approach, Dardick et al. identified a tiller angle control 1 (TAC1) gene which controls the branch angle and affects tree architecture in peach [21].

\subsection{The transcriptome}

Following the determination of the genome sequence, the next stage in the investigation of gene function is transcriptome analysis. The hybridization- or sequencebased approaches constituted the most two popular platforms to deduce and quantify gene expression. In contrast to hybridization-based methods, sequence-based approaches directly determine the cDNA sequence and its abundance. The Next-Gen sequencing methods have provided a new approach (RNA-sequencing or RNA-seq) for both mapping and quantifying transcriptomes, which has clear advantages over existing approaches. Fruit crops have complex genetic backgrounds and are highly heterozygous by nature. By reducing this complexity, in combination with exquisite experimental design, transcriptome analysis can provide information about traits of interest.

RNA-Seq is rapidly becoming the primary approach for transcriptome research since it provides a more thorough and scientific representation of the absolute transcript population, and is more sensitive to genes expressed at low levels. Moreover, prior gene sequence information is not required. Exploration of RNA-Seq in fruit crops demonstrated its advantages over other techniques [22,23]. RNA- seq has been widely applied for the dissection of various traits, such as disease resistance [24], fruit development [25] and the columnar feature of certain trees [26].

\subsection{The proteome}

Proteomics yields information about the expression and function of proteins that is important for understanding the molecular basis of metabolic and biochemical behavior in plants.

Proteomic analysis has been utilized to study the molecular mechanisms underlying fruit development and ripening. Citrus provides a representative non-climacteric fruit crop. Comprehensive proteomic analysis with LCMS/MS identified 1400 proteins from different fractions of fruit juice cells [27], and a similar technique was used to explore the possible molecular mechanism underlying carotenoid accumulation [28] and anthocyanin accumulation [29] in citrus fruits at different ripening stages.

Information gained from the proteome is most powerful when it is combined with that from other omics tools. For example, in grape, the abundance of proteins involved in sugar (such as fructose) and organic acid (such as malate) was found to correlate with metabolite levels [30]. In citrus fruit, storage at low temperature was found to result in the upregulation of stress-responsive genes, arrested signal transduction, and inhibited primary metabolism, secondary metabolism, and the transportation of metabolites [31].

Proteomics has also been used to dissect the proteins involved in biotic and abiotic stress responses. In citrus, a plant natriuretic peptide-like molecule of the pathogen Xanthomonas axonopodis pv. citri induced rapid changes in host photosynthesis at the protein expression [32]. In papaya, two-dimensional gel electrophoresis, difference gel electrophoresis and label-free quantitative proteomics were used to investigate the influence of the sticky disease pathogen (Papaya meleira virus) on leaves and papaya latex [33]. Other abiotic stresses have also been widely investigated by proteomic approaches, such as salinity [34].

\section{5 miRNA}

microRNAs (miRNAs), which are RNA molecules composed of 20-24 nucleotides (nt), regulate gene expression by cleaving target mRNAs or by inhibiting their translation. Various miRNAs act as negative regulators in plant development and stress responses, including miR156, miR159 and miR172, which are involved in flower development, particularly with respect to flowering time regulation and the phase change from vegetative growth to reproductive growth [35].

miRNAs were discovered using cloning and sequencing methods, and computational prediction of miRNA precursors, pri-miRNAs, from ESTs or whole genome sequences were performed in a wide range of fruit crops 
[36,37]. Next-Gen sequencing technology provides highthroughput identification of miRNAs (by small RNA sequencing) and their targets (miRNA-mediated degraded fragment sequencing, degradome). Comparative analysis of miRNAomes in sweet orange between a red-flesh mutant and the wild type suggested that miRNA-mediated regulation is involved in fruit color determination [38]. Pantaleo et al. [39] deep-sequenced miRNAs in the leaf, tendril, inflorescence, and berry of grapevine, and from these data postulated that Vvi-miR395 plays a vital role in tendril development, particularly with respect to the climbing function. In apple, small RNA sequencing enabled the discovery of three miRNAs and phased small interfering RNAs, siRNAs, which interact with diverse MYB genes that form regulatory networks to regulate various genes [40].

Artificial miRNAs provide flexible tools for effective post-transcriptional gene silencing (PTGS) in plants. Since miRNAs recognize target genes with imperfect complementary matches, artificial miRNA can be designed to target one or several target genes [41]. Pre-miR159 and pre-miR319 are used as a classical backbone to create artificial miRNAs because they are conserved in diverse species and incorporate a stable stem-loop structure [41]. Further information regarding design of artificial miRNA can be found using the Web MicroRNA Designer, WMD3 [42]. In fruit crops, artificial miRNA has been used to impart virus resistance. For example [43], designed two artificial miRNAs targeting the coat protein gene of the grapevine fan-leaf virus. For the most part, the fruit crop miRNAs in miRBase [44] were annotated using bioinformatic and sequencing approaches, but direct evidence from gene function experiments is still lacking.

\subsection{The epigenome}

Epigenetic markers are present on both DNA and associated histones and include DNA methylation, histone modification, and certain aspects of small interfering RNA pathways [45].

It is widely reported that DNA methylation occurs during micropropagation or long-term cryopreservation [46]. A change in the DNA methylation pattern during tree aging has also been reported for several species; in Castanea sativa, the global DNA methylation level of juvenile tree shoots is much lower than that of mature-tree and dormancy shoots [47], and in crab apple seeding trees results suggest that demethylation may occur during the adult phase [48]. In addition, several studies have shown that DNA methylation also plays an important role in the genetic regulation of fruit plant secondary metabolism. For example, the promoter of the anthocyanin regulator gene MYB10 is highly methylated in green strips of apple peel [49]. In Vitis amurensis, DNA methylation may be involved in controlling resveratrol biosynthesis [50]. A recent noteworthy study showed that the methylation in the promoter region of the MYB transcription factor in pear is associated with green-skinned mutation and involved in the regulation of anthocyanin production in the outer pericarp [51].

\section{Future perspectives}

Dramatic advancements in genomics are likely to drive a wave of fruit crop research in the near future. A further increases in the power and capacity of Next-Gen sequencing technology is likely to markedly reduce the cost of sequencing from the current 300 RMB per gigabase. We anticipate that on one hand, many de novo genomes will be revealed, such as chestnut, Chinese date, litchi and walnut among others. Heterozygosity should be carefully considered as one of the challenging factors in such project. Heterozygosity can be significantly reduced by prior work including successive inbreeding or doublehaploid induction. The latter provide homozygous genotypes, which greatly reduce genome complexity and facilitate genome assembly. On the other hand, referencegenome based studies will stimulate burgeoning research, e.g., epigenome, and ultimately, genome re-sequencing analysis will become a common approach to dissect agronomic traits in fruit crops (summarized in Fig. 1). Large segregant and natural populations will be needed for fast and efficient genomic sequencing to identify the genes controlling agronomic/biological traits and to elucidate the underlying genetic architecture and mechanisms.

Omics-based studies will provide more specific results and may even yield information at the single cell level. Most current genetic studies consider one individual with homogenous DNA; however, recent studies have revealed heterogeneity in the composition of variants even within individual. This observation is particularly true for human cancer genomics [52]. Consequently, to reduce the heterogeneity and increase the chance of identification of causal genetic events, the sampling strategy should be as specific as possible to facilitate the pinpointing of the trait of interest. For long-lived perennial fruit trees, a relatively high level of somatic mutations accumulate during cultivation; with bud or limb mutations observed frequently in the vegetatively propagated trees. Therefore, researchers should be careful to avoid casual sampling even within a single tree. Samples for genomic studies should be restricted to the smallest possible area.

Biological replicates are required for transcriptome, proteome and small RNA studies; however, most published results only included two biological replicates. We suggest that future experiments include at least three biological replicates so that the statistical analysis of genomic data can be performed with greater power and confidence. As the cost of Next-Gen sequencing has dropped considerably, more replicates can be analyzed, which is increasingly required for the publication of 
genome studies. A recent study of confidence-based somatic mutation evaluation demonstrated that inclusion of genome sequencing replicates will increase the confidence statistical comparisons and the identification of somatic mutations [53].

We anticipate that many important agronomic traits will be investigated by genomics and functional studies. Biological questions that are unique to fruit crops and cannot be addressed in model plants such as Arabidopsis, will be particularly worthy of investigation. The trait of interest will vary from plant to plant, but the following traits would attract more interest: regulation of flowering stage (the transition from juvenile to reproduction), fruit quality (color, aroma, flavor and texture), fruit size and structure, fruit development and ripening, the interaction between the rootstock and scion, the chimera mechanism, the asexual reproduction, and secondary metabolites beneficial for human health.

\begin{abstract}
Acknowledgements The National Natural Science Foundation of China (31330066, 31221062 and 31222047) provided financial support for this study. Jidi Xu, Yuanlong Liu and Keqin Yu are thanked for helpful discussion on the epigenetics, miRNA and transcriptome sections, respectively.

Compliance with ethics guidelines Qiang Xu, Chaoyang Liu, Manosh Kumar Biswas, Zhiyong Pan and Xiuxin Deng declare that they have no conflict of interest or financial conflicts to disclose.

This article is a review and does not contain any studies with human or animal subjects performed by the any of the authors.
\end{abstract}

\section{References}

1. Varshney R K, Nayak S N, May G D, Jackson S A. Next-generation sequencing technologies and their implications for crop genetics and breeding. Trends in Biotechnology, 2009, 27(9): 522-530

2. Ming R, Hou S B, Feng Y, Yu Q Y, Dionne-Laporte A, Saw J H, Senin P, Wang W, Ly B V, Lewis K L T, Salzberg S L, Feng L, Jones M R, Skelton R L, Murray J E, Chen C X, Qian W B, Shen J G, Du P, Eustice M, Tong E, Tang H B, Lyons E, Paull R E, Michael T P, Wall K, Rice D W, Albert H, Wang M L, Zhu Y J, Schatz M, Nagarajan N, Acob R A, Guan P Z, Blas A, Wai C M, Ackerman C M, Ren Y, Liu C, Wang J M, Wang J P, Na J K, Shakirov E V, Haas B, Thimmapuram J, Nelson D, Wang X Y, Bowers J E, Gschwend A R, Delcher A L, Singh R, Suzuki J Y, Tripathi S, Neupane K, Wei H R, Irikura B, Paidi M, Jiang N, Zhang W L, Presting G, Windsor A, Navajas-Perez R, Torres M J, Feltus F A, Porter B, Li Y J, Burroughs A M, Luo M C, Liu L, Christopher D A, Mount S M, Moore P H, Sugimura T, Jiang J M, Schuler M A, Friedman V, Mitchell-Olds T, Shippen D E, dePamphilis C W, Palmer J D, Freeling M, Paterson A H, Gonsalves D, Wang L, Alam M. The draft genome of the transgenic tropical fruit tree papaya (Carica papaya Linnaeus). Nature, 2008, 452(7190): 991-996

3. Xu Q, Chen L L, Ruan X, Chen D, Zhu A, Chen C, Bertrand D, Jiao W B, Hao B H, Lyon M P, Chen J, Gao S, Xing F, Lan H, Chang J W, Ge X, Lei Y, Hu Q, Miao Y, Wang L, Xiao S, Biswas M K, Zeng
W, Guo F, Cao H, Yang X, Xu X W, Cheng Y J, Xu J, Liu J H, Luo O J, Tang Z, Guo W W, Kuang H, Zhang H Y, Roose M L, Nagarajan N, Deng X X, Ruan Y. The draft genome of sweet orange (Citrus sinensis). Nature Genetics, 2013, 45(1): 59-66

4. Shulaev V, Sargent D J, Crowhurst R N, Mockler T C, Folkerts O, Delcher A L, Jaiswal P, Mockaitis K, Liston A, Mane S P, Burns P, Davis T M, Slovin J P, Bassil N, Hellens R P, Evans C, Harkins T, Kodira C, Desany B, Crasta O R, Jensen R V, Allan A C, Michael T P, Setubal J C, Celton J M, Rees D J G, Williams K P, Holt S H, Rojas J J R, Chatterjee M, Liu B, Silva H, Meisel L, Adato A, Filichkin S A, Troggio M, Viola R, Ashman T L, Wang H, Dharmawardhana P, Elser J, Raja R, Priest H D, Bryant D W, Fox S E, Givan S A, Wilhelm L J, Naithani S, Christoffels A, Salama D Y, Carter J, Girona E L, Zdepski A, Wang W Q, Kerstetter R A, Schwab W, Korban S S, Davik J, Monfort A, Denoyes-Rothan B, Arus P, Mittler R, Flinn B, Aharoni A, Bennetzen J L, Salzberg S L, Dickerman A W, Velasco R, Borodovsky M, Veilleux R E, Folta K $\mathrm{M}$. The genome of woodland strawberry (Fragaria vesca). Nature Genetics, 2011, 43(2): 109-116

5. Velasco R, Zharkikh A, Affourtit J, Dhingra A, Cestaro A, Kalyanaraman A, Fontana P, Bhatnagar S K, Troggio M, Pruss D, Salvi S, Pindo M, Baldi P, Castelletti S, Cavaiuolo M, Coppola G, Costa F, Cova V, Dal Ri A, Goremykin V, Komjanc M, Longhi S, Magnago P, Malacarne G, Malnoy M, Micheletti D, Moretto M, Perazzolli M, Si-Ammour A, Vezzulli S, Zini E, Eldredge G, Fitzgerald L M, Gutin N, Lanchbury J, Macalma T, Mitchell J T, Reid J, Wardell B, Kodira C, Chen Z, Desany B, Niazi F, Palmer M, Koepke T, Jiwan D, Schaeffer S, Krishnan V, Wu C, Chu V T, King S T, Vick J, Tao Q, Mraz A, Stormo A, Stormo K, Bogden R, Ederle D, Stella A, Vecchietti A, Kater M M, Masiero S, Lasserre P, Lespinasse Y, Allan A C, Bus V, Chagne D, Crowhurst R N, Gleave A P, Lavezzo E, Fawcett J A, Proost S, Rouze P, Sterck L, Toppo S, Lazzari B, Hellens R P, Durel C E, Gutin A, Bumgarner R E, Gardiner S E, Skolnick M, Egholm M, Van de Peer Y, Salamini F, Viola R. The genome of the domesticated apple (Malus $\times$ domestica Borkh.). Nature Genetics, 2010, 42(10): 833-839

6. D'Hont A, Denoeud F, Aury J M, Baurens F C, Carreel F, Garsmeur O, Noel B, Bocs S, Droc G, Rouard M, Da Silva C, Jabbari K, Cardi C, Poulain J, Souquet M, Labadie K, Jourda C, Lengelle J, RodierGoud M, Alberti A, Bernard M, Correa M, Ayyampalayam S, McKain M R, Leebens-Mack J, Burgess D, Freeling M, Mbeguie A M D, Chabannes M, Wicker T, Panaud O, Barbosa J, Hribova E, Heslop-Harrison P, Habas R, Rivallan R, Francois P, Poiron C, Kilian A, Burthia D, Jenny C, Bakry F, Brown S, Guignon V, Kema G, Dita M, Waalwijk C, Joseph S, Dievart A, Jaillon O, Leclercq J, Argout X, Lyons E, Almeida A, Jeridi M, Dolezel J, Roux N, Risterucci A M, Weissenbach J, Ruiz M, Glaszmann J C, Quetier F, Yahiaoui N, Wincker P. The banana (Musa acuminata) genome and the evolution of monocotyledonous plants. Nature, 2012, 488 (7410): 213-217

7. Al-Dous E K, George B, Al-Mahmoud M E, Al-Jaber M Y, Wang H, Salameh Y M, Al-Azwani E K, Chaluvadi S, Pontaroli A C, Debarry J, Arondel V, Ohlrogge J, Saie I J, Suliman-Elmeer K M, Bennetzen J L, Kruegger R R, Malek J A. De novo genome sequencing and comparative genomics of date palm (Phoenix dactylifera). Nature Biotechnology, 2011, 29(6): 521-527 
8. Verde I, Abbott A G, Scalabrin S, Jung S, Shu S, Marroni F, Zhebentyayeva T, Dettori M T, Grimwood J, Cattonaro F, Zuccolo A, Rossini L, Jenkins J, Vendramin E, Meisel L A, Decroocq V, Sosinski B, Prochnik S, Mitros T, Policriti A, Cipriani G, Dondini L, Ficklin S, Goodstein D M, Xuan P, Fabbro C D, Aramini V, Copetti D, Gonzalez S, Horner D S, Falchi R, Lucas S, Mica E, Maldonado J, Lazzari B, Bielenberg D, Pirona R, Miculan M, Barakat A, Testolin R, Stella A, Tartarini S, Tonutti P, Arus P, Orellana A, Wells C, Main D, Vizzotto G, Silva H, Salamini F, Schmutz J, Morgante M, Rokhsar D S. The high-quality draft genome of peach (Prunus persica) identifies unique patterns of genetic diversity, domestication and genome evolution. Nature Genetics, 2013, 45(5): 487-494

9. Wu J, Wang Z, Shi Z, Zhang S, Ming R, Zhu S, Khan M A, Tao S, Korban S S, Wang H, Chen N J, Nishio T, Xu X, Cong L, Qi K, Huang X, Wang Y, Zhao X, Deng C, Gou C, Zhou W, Yin H, Qin G, Sha Y, Tao Y, Chen H, Yang Y, Song Y, Zhan D, Wang J, Li L, Dai M, Gu C, Shi D, Wang X, Zhang H, Zeng L, Zheng D, Wang C, Chen M, Wang G, Xie L, Sovero V, Sha S, Huang W, Zhang M, Sun J, Xu L, Li Y, Liu X, Li Q, Shen J, Paull R E, Bennetzen J L, Wang J, Zhang S L. The genome of the pear (Pyrus bretschneideri Rehd.). Genome Research, 2013, 23(2): 396-408

10. Huang S, Ding J, Deng D, Tang W, Sun H, Liu D, Zhang L, Niu X, Zhang X, Meng M, Yu J, Liu J, Han Y, Shi W, Zhang D, Cao S, Wei Z, Cui Y, Xia Y, Zeng H, Bao K, Lin L, Min Y, Zhang H, Miao M, Tang X, Zhu Y, Sui Y, Li G, Sun H, Yue J, Sun J, Liu F, Zhou L, Lei L, Zheng X, Liu M, Huang L, Song J, Xu C, Li J, Ye K, Zhong S, Lu B R, He G, Xiao F, Wang H L, Zheng H, Fei Z, Liu Y. Draft genome of the kiwifruit Actinidia chinensis. Nature Communications, 2013, 4: 2640

11. Jaillon O, Aury J M, Noel B, Policriti A, Clepet C, Casagrande A, Choisne N, Aubourg S, Vitulo N, Jubin C, Vezzi A, Legeai F, Hugueney P, Dasilva C, Horner D, Mica E, Jublot D, Poulain J, Bruyere C, Billault A, Segurens B, Gouyvenoux M, Ugarte E, Cattonaro F, Anthouard V, Vico V, Del Fabbro C, Alaux M, Di Gaspero G, Dumas V, Felice N, Paillard S, Juman I, Moroldo M, Scalabrin S, Canaguier A, Le Clainche I, Malacrida G, Durand E, Pesole G, Laucou V, Chatelet P, Merdinoglu D, Delledonne M, Pezzotti M, Lecharny A, Scarpelli C, Artiguenave F, Pe M E, Valle G, Morgante M, Caboche M, Adam-Blondon A F, Weissenbach J, Quetier F, Wincker P. The grapevine genome sequence suggests ancestral hexaploidization in major angiosperm phyla. Nature, 2007, 449(7161): 463-467

12. Chen C, Bowman K D, Choi Y A, Dang P M, Rao M N, Huang S, Soneji J R, McCollum T G, Gmitter Jr F G. EST-SSR genetic maps for Citrus sinensis and Poncirus trifoliata. Tree Genetics \& Genomes, 2008, 4(1): 1-10

13. Ollitrault P, Terol J, Chen C, Federici C T, Lotfy S, Hippolyte I, Ollitrault F, Brard A, Chauveau A, Cuenca J, Costantino G, Kacar Y, Mu L, Garcia-Lor A, Froelicher Y, Aleza P, Bolan A, Billot C, Navarro L, Luro F, Roose M, Gmitter F, Talon M, Brunel D. A reference genetic map of $C$. clementina hort. ex Tan.; citrus evolution inferences from comparative mapping. BMC Genomics, 2012, 13(1): 593

14. .da Maia L C, Palmieri D A, Souza V Q, Kopp M M, Carvalho F I F, Costa de Oliveira A. SSR Locator: Tool for simple sequence repeat discovery integrated with primer design and PCR simulation.
International Journal of Plant Genomics, 2008: 412696

15. Christoph M. Phobos - A tandem repeat search tool for complete genomes. Available at RUHR-Univertsity Bochum website on March 26, 201426

16. Biswas M K, Chai L, Mayer C, Xu Q, Guo W, Deng X. Exploiting BAC-end sequences for the mining, characterization and utility of new short sequences repeat (SSR) markers in Citrus. Molecular Biology Reports, 2012, 39(5): 5373-5386

17. Zorrilla-Fontanesi Y, Cabeza A, Torres A M, Botella M A, Valpuesta V, Monfort A, Snchez-Sevilla J F, Amaya I. Development and bin mapping of strawberry genic-SSRs in diploid Fragaria and their transferability across the Rosoideae subfamily. Molecular Breeding, 2011, 27(2): 137-156

18. Myles S, Boyko A R, Owens C L, Brown P J, Grassi F, Aradhya M K, Prins B, Reynolds A, Chia J M, Ware D, Bustamante C D, Buckler E S. Genetic structure and domestication history of the grape. Proceedings of the National Academy of Sciences of the United States of America, 2011, 108(9): 3530-3535

19. Ahmad R, Parfitt D E, Fass J, Ogundiwin E, Dhingra A, Gradziel T M, Lin D, Joshi N A, Martinez-Garcia P J, Crisosto C H. Whole genome sequencing of peach (Prunus persica L.) for SNP identification and selection. BMC Genomics, 2011, 12(1): 569

20. Kumar S, Garrick D J, Bink M C, Whitworth C, Chagn D, Volz R K. Novel genomic approaches unravel genetic architecture of complex traits in apple. BMC Genomics, 2013, 14(1): 393

21. Dardick C, Callahan A, Horn R, Ruiz K B, Zhebentyayeva T, Hollender C, Whitaker M, Abbott A, Scorza R. PpeTAC1 promotes the horizontal growth of branches in peach trees and is a member of a functionally conserved gene family found in diverse plants species. Plant Journal, 2013, 75(4): 618-630

22. Xu Q, Yu K, Zhu A, Ye J, Liu Q, Zhang J, Deng X. Comparative transcripts profiling reveals new insight into molecular processes regulating lycopene accumulation in a sweet orange (Citrus sinensis) red-flesh mutant. BMC Genomics, 2009, 10(1): 540

23. Zenoni S, Ferrarini A, Giacomelli E, Xumerle L, Fasoli M, Malerba G, Bellin D, Pezzotti M, Delledonne M. Characterization of transcriptional complexity during berry development in Vitis vinifera using RNA-Seq. Plant Physiology, 2010, 152(4): 17871795

24. Martinelli F, Uratsu S L, Albrecht U, Reagan R L, Phu M L, Britton M, Buffalo V, Fass J, Leicht E, Zhao W, Lin D, D’Souza R, Davis C E, Bowman K D, Dandekar A M. Transcriptome profiling of citrus fruit response to huanglongbing disease. PLOS ONE, 2012, 7(5): e38039

25. Yu K, Xu Q, Da X, Guo F, Ding Y, Deng X. Transcriptome changes during fruit development and ripening of sweet orange (Citrus sinensis). BMC Genomics, 2012, 13(1): 10

26. Krost C, Petersen R, Lokan S, Brauksiepe B, Braun P, Schmidt E R. Evaluation of the hormonal state of columnar apple trees (Malus $\times$ domestica) based on high throughput gene expression studies. Plant Molecular Biology, 2013, 81(3): 211-220

27. Katz E, Fon M, Lee Y, Phinney B, Sadka A, Blumwald E. The citrus fruit proteome: insights into citrus fruit metabolism. Planta, 2007, 226(4): 989-1005

28. Pan Z, Zeng Y, An J, Ye J, Xu Q, Deng X. An integrative analysis of transcriptome and proteome provides new insights into carotenoid 
biosynthesis and regulation in sweet orange fruits. Journal of Proteomics, 2012, 75(9): 2670-2684

29. Muccilli V, Licciardello C, Fontanini D, Russo M P, Cunsolo V, Saletti R, Reforgiato Recupero G, Foti S. Proteome analysis of Citrus sinensis L.(Osbeck) flesh at ripening time. Journal of Proteomics, 2009, 73(1): 134-152

30. Martnez-Esteso M J, Sells-Marchart S, Lijavetzky D, Pedreo M A, Bru-Martnez R. A DIGE-based quantitative proteomic analysis of grape berry flesh development and ripening reveals key events in sugar and organic acid metabolism. Journal of Experimental Botany, 2011, 62(8): 2521-2569

31. Yun Z, Jin S, Ding Y, Wang Z, Gao H, Pan Z, Xu J, Cheng Y, Deng $X$. Comparative transcriptomics and proteomics analysis of citrus fruit, to improve understanding of the effect of low temperature on maintaining fruit quality during lengthy post-harvest storage. Journal of Experimental Botany, 2012, 63(8): 2873-2893

32. Garavaglia B S, Thomas L, Zimaro T, Gottig N, Daurelio L D, Ndimba B, Orellano E G, Ottado J, Gehring C. A plant natriuretic peptide-like molecule of the pathogen Xanthomonas axonopodis pv. citri causes rapid changes in the proteome of its citrus host. $B M C$ Plant Biology, 2010, 10(1): 51

33. Rodrigues S P, Ventura J A, Aguilar C, Nakayasu E S, Choi H, Sobreira T J, Nohara L L, Wermelinger L S, Almeida I C, Zingali R B, Fernandes P M. Label-free quantitative proteomics reveals differentially regulated proteins in the latex of sticky diseased Carica papaya L. plants. Journal of Proteomics, 2012, 75(11): 3191-3198

34. Tanou G, Filippou P, Belghazi M, Job D, Diamantidis G, Fotopoulos V, Molassiotis A. Oxidative and nitrosative-based signaling and associated post-translational modifications orchestrate the acclimation of citrus plants to salinity stress. Plant Journal, 2012, 72(4): 585-599

35. Chuck G, O'Connor D. Small RNAs going the distance during plant development. Current Opinion in Plant Biology, 2010, 13(1): 40-45

36. Carra A, Mica E, Gambino G, Pindo M, Moser C, Pè M E, Schubert A. Cloning and characterization of small non-coding RNAs from grape. Plant Journal, 2009, 59(5): 750-763

37. Song $\mathrm{C}$, Fang $\mathrm{J}$, Li X, Liu H, Chao C T. Identification and characterization of 27 conserved microRNAs in citrus. Planta, 2009, 230(4): 671-685

38. Xu Q, Liu Y, Zhu A, Wu X, Ye J, Yu K, Guo W, Deng X. Discovery and comparative profiling of microRNAs in a sweet orange red-flesh mutant and its wild type. BMC Genomics, 2010, 11(1): 246

39. Pantaleo V, Szittya G, Moxon S, Miozzi L, Moulton V, Dalmay T, Burgyan J. Identification of grapevine microRNAs and their targets using high-throughput sequencing and degradome analysis. Plant
Journal, 2010, 62(6): 960-976

40. Xia R, Zhu H, An Y, Beers E P, Liu Z. Apple miRNAs and tasiRNAs with novel regulatory networks. Genome Biology, 2012, 13(6): R47

41. Schwab R, Ossowski S, Riester M, Warthmann N, Weigel D. Highly specific gene silencing by artificial microRNAs in Arabidopsis. Plant Cell, 2006, 18(5): 1121-1133

42. WMD3-Web app for the automated design of artificial microRNAs. Available at WeigelWorld website on March 26, 2014

43. Jelly N S, Schellenbaum P, Walter B, Maillot P. Transient expression of artificial microRNAs targeting Grapevine fanleaf virus and evidence for RNA silencing in grapevine somatic embryos. Transgenic Research, 2012, 21(6): 1319-1327

44. MiRBase: the microRNA database. Available at Mirbase website on March 26, 201426

45. Henderson I R, Jacobsen S E. Epigenetic inheritance in plants. Nature, 2007, 447(7143): 418-424

46. Kaity A, Ashmore S, Drew R A, Dulloo M. Assessment of genetic and epigenetic changes following cryopreservation in papaya. Plant Cell Reports, 2008, 27(9): 1529-1539

47. Hasbn R, Valledor L, Berdasco M, Santamara E, Caal M, Rodrguez $\mathrm{R}$, Rios D, Snchez M. In vitro proliferation and genome DNA methylation in adult chestnuts. Acta Horticulturae, 2005, 693: 333

48. Hafiz I A, Abbasi N A, Ahmad T, Hussain A. DNA methylation profiles differ between juvenile and adult phase leaves of crab apple (Malus micromalus) seedling tree. Pakistan Journal of Botany, 2008, 40(3): 1025-1032

49. Telias A, Lin-Wang K, Stevenson D E, Cooney J M, Hellens R P, Allan A C, Hoover E E, Bradeen J M. Apple skin patterning is associated with differential expression of MYB10. BMC Plant Biology, 2011, 11(1): 93

50. Kiselev K V, Tyunin A P, Zhuravlev Y N. Involvement of DNA methylation in the regulation of STS10 gene expression in Vitis amurensis. Planta, 2013, 237(4): 933-941

51. Wang Z, Meng D, Wang A, Li T, Jiang S, Cong P, Li T. The methylation of the PcMYB10 promoter is associated with greenskinned sport in Max Red Bartlett pear. Plant Physiology, 2013, 162 (2): 885-896

52. Vogelstein B, Papadopoulos N, Velculescu V E, Zhou S, Diaz L A, Kinzler K W. Cancer genome landscapes. Science, 2013, 339 (6127): 1546-1558

53. Löwer M, Renard B Y, de Graaf J, Wagner M, Paret C, Kneip C, Türeci ö, Diken M, Britten C, Kreiter S, Koslowski M, Castle J C, Sahin U. Confidence-based somatic mutation evaluation and prioritization. PLoS Computational Biology, 2012, 8(9): e1002714 